\title{
Rechtsgeschichte
}

http://www.rg-rechtsgeschichte.de/rg1

Zitiervorschlag: Rechtsgeschichte Rg 1 (2002)

$\operatorname{Rg} 2002 \quad 34-34$

http://dx.doi.org/10.12946/rg01/034-034

\section{Egon Flaig}

».. ziehe ich es vor, dazu zu schweigen ...» 


\section{»... ziehe ich es vor, dazu zu schweigen ..."}

"Sehr geehrte Frau Emmerich,

nach eingehender Lektüre des Textes ziehe ich es vor, dazu zu schweigen. Hier in Deutschland greift jetzt die Systemtheorie um sich, das ist besser als die entsetzliche Theorielosigkeit, unter der wir so lange litten. Aber als Praxeologe Bourdieuscher Prägung ist für mich Systemtheorie ein zu grober Keil angesichts der Fragen, die ich stelle. Auseinandersetzung hat sich in der Regel als sinnlos erwiesen, weil systemtheore- tisch verfahrende Kollegen auf der Mikro-Ebene in der Regel nichts zu sagen haben. Das ist aber die analytisch entscheidende Ebene. Bleibt der letzte Punkt von Frau Fögen. Dazu habe ich mich im RJ geäußert und will mich nicht wiederholen. Ich halte es mit Walter Benjamin: Über-zeugen ist unfruchtbar ... Seien Sie freundlich gegrüßt! e. flaig «

Egon Flaig*

* Professor für Alte Geschichte an der Ernst-Moritz-Arndt-Universität Greifswald. 